\title{
Thirty years of surgery for carcinoma of the bronchus
}

\author{
JR BELCHER
}

From the London Chest and Middlesex Hospitals, London

ABSTRACT A study has been made of 8781 patients with bronchial carcinoma who were operated on by seven surgeons in England during the years $1949-80$. There were 3865 pneumonectomies, 3790 lobectomies, and 1126 thoracotomies. During this period the operative mortality has fallen. Neither the resection rate nor the proportion of lobectomies bears any relation to the survival $\omega_{\infty}$ rate in any series. There has been remarkable similarity between the various survival rates in that ${ }^{\circ} \circ$ the difference at five years was only $1.3 \%(25 \cdot 5-26.8 \%)$ and at 10 years $4.2 \%(13 \cdot 6-17 \cdot 8 \%)$. These figures are reflected in reports published worldwide, where there is also great similarity $\infty$ between the results. If the improvement in operative mortality is excluded, there has been no improvement in the survival rates in the last thirty years.

The incidence of bronchial carcinoma has risen steadily in many countries during the last 30 years. In the United Kingdom it has been the commonest neoplasm among men for a long time; among women it is now second only to carcinoma of the breast and the gap is narrowing. We therefore thought it would be worthwhile to study the results of surgery for this disease performed by a group of surgeons in England during this period, to see whether the results had improved and to look at some other factors which might be of interest to future generations.

\section{Material and operative trends}

Reports were received from seven surgeons on 8781 patients who had been operated on for bronchial carcinoma from 1949 to 1980 (table 1). All the surgeons worked in or around London, except for one (RAS) who was based in Coventry. Each was asked to give the total number of patients in his series, the operative mortality, the resection rate, the proportion of lobectomies, and the survival rates at five and 10 years and subsequently. Two of the surgeons were also able to give the causes of late death in their patients. Not all the contributors could give all details, but follow-up data were available for 8121 operations (92\%). There were 3865 pneumon-

Based on a presidential address given to the Society of Thoracic and Cardiovascular Surgeons in Newcastle upon Tyne in September 1981.

Address for reprint requests: Mr JR Belcher, 23 Hornton Court, Hornton Street, London W8.

Accepted 20 January 1983 ectomies, 3790 lobectomies, and 1126 thoracotomies.

OPERATIVE MORTALITY

Table 1 shows the operative mortality for the individual surgeons and illustrates one consistent finding in this investigation-namely, the close similarity of $\stackrel{\mathbb{Q}}{\mathbb{Q}}$ results. Where a breakdown of the figures was given, $\vec{\overrightarrow{ }}$ it showed that the combined operative mortality rate $\frac{3}{3}$ for lobectomy was $5.7 \%$, for pneumonectomy $11.7 \%$, and for thoracotomy $4 \%$. Several of the con-o tributors noted that the mortality had fallen as time passed, and figure 1 shows my own results in fiveyear groups. The mortality for lobectomy has changed little, but the death rate for pneumonec- $\frac{0}{\sigma}$ tomy has fallen from $13 \%$ during the first six years to $7 \%$ in the last five. This change has been due largely to improvements in postoperative care and the introduction of artificial ventilation towards the 0 end of the 1950s. Nevertheless, although the mortality corresponds closely with that reported fromo other centres in Britain and the United States ${ }^{1-3}$

Table 1 Contributors to the series

\begin{tabular}{|c|c|c|}
\hline Surgeon & No of cases & $\begin{array}{l}\text { Operative } \\
\text { morality (\%) }\end{array}$ \\
\hline $\begin{array}{l}\text { M Bates (MB) } \\
\text { MM Brown,R Rowlandson } \\
\text { (MMB, RR) } \\
\text { LL Bromley (LLB) } \\
\text { JR Belcher (JRB) } \\
\text { CA Jackson (CAJ) } \\
\text { R Abbey Smith (RAS) }\end{array}$ & $\begin{array}{r}2430 \\
\\
1058 \\
660 \\
2097 \\
836 \\
1700\end{array}$ & $\begin{array}{l}9.2 \\
8.2 \\
7.5 \\
9.0 \\
8.0 \\
7.0\end{array}$ \\
\hline Total & 8781 & \\
\hline
\end{tabular}




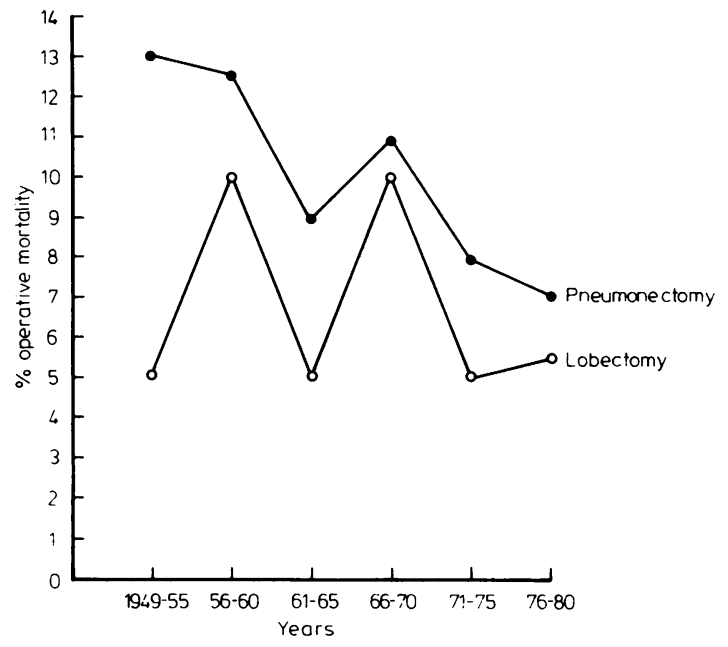

Fig 1 Operative mortality for pneumonectomy and lobectomy in five-year groups (author's figures).

(see also UK Register of Thoracic Surgery, 1980), it remains much higher than in most other branches of surgery.

\section{RESECTION AND LOBECTOMY RATES}

Because one of the principal contributors to this study was the first advocate of the policy of "resection at all costs" 4 the resection rate was relatively high $(87.6 \%)$, although it varied more widely than the operative mortality (table 2 ). The variation in resection rate among the contributors reflects the differences in policy among them regarding such factors as the age of the patients offered surgery and whether individual surgeons would do a resection in the face of widespread disease. Where the resection rate was high the operative mortality might have been expected to be high also; but this was not so-indeed, the highest resection rate was associated with the lowest operative mortality.

The first paper advocating the policy "lobectomy where possible" in the treatment of bronchial carcinoma came from one of these surgeons ${ }^{5}$ at a time when pneumonectomy was thought to be the treatment of choice in all cases. This policy was adopted

Table 2 Resection and lobectomy rates

\begin{tabular}{lll}
\hline Surgeon & $\begin{array}{l}\text { Resection } \\
\text { rate }(\%)\end{array}$ & $\begin{array}{l}\text { Lobectomy } \\
\text { rate }(\%)\end{array}$ \\
\hline MB & 91 & 43 \\
MMB, RR & 83 & 78 \\
LLB & 86 & 45 \\
JRB & 78 & 50 \\
CAJ & 90 & 38 \\
RAS & 97.5 & 48 \\
\hline
\end{tabular}

from the start by most surgeons contributing to this series and this accounts for the high proportion of lobectomies $(50 \%)$, although the variation within the group is wide (table 2 ). A higher resection rate tended to go with a lower lobectomy rate, but differences of opinion about the criteria for operation also played a part. More recently there has been a trend towards even more conservative surgery in the form of segmental resection ${ }^{6}$ but as there were few such cases in this series they have been included with lobectomies.

\section{Results}

SURVIVAL

The figures given here are based on actual survival, the number of patients alive after operation at the end of the period under consideration being expressed as a percentage of those at risk; the operative mortality is excluded. Patients lost to follow-up are assumed to be dead; there were seven in the series of 2430 of Bates ${ }^{7}$ and only one in the series of 1700 of Abbey Smith. ${ }^{8}$ Table 3 shows the survival rates reported by the seven surgeons. Their similarity is remarkable, with a difference of only $1.3 \%$ between the highest and the lowest at five years, although there is a slightly wider variation at $\mathbf{1 0}$ years. At 20 years the numbers at risk were smaller, but apart from the $11.5 \%$ of CAJ they remain similar. Lastly, there has been no change in the survival rate during the 30 years under consideration. My own five-year survival rate for $1950-5$ was $28 \%$ and for $1970-5$ $27 \%$, while the 10 -year rate remained unaltered at $15 \%$.

As those surgeons who had a relatively low resection rate had not removed the more advanced growths, they might be expected to have a higher survival rate than their more aggressive colleagues. This was not shown to be so (fig 2). Similarly, if lobectomy were an inadequate operation in the treatment of bronchial carcinoma, the series with the largest proportion of these might be expected to have had the lowest survival rate. This again was not shown to be so (fig 3 ). Thus the twin policies of "resection at all costs" and "lobectomy where possible" seem to have been vindicated.

Table 3 Survival rates (operative mortality excluded)

\begin{tabular}{lllc}
\hline Surgeon & \multicolumn{3}{l}{ Survival rate $(\%)$ at } \\
\cline { 2 - 4 } & 5 years & 10 years & 20 years \\
\hline MB & 26.2 & 17.3 & 6 \\
MMB, RR & 25.5 & 13.6 & 0 \\
JRB & 26.8 & 16 & 3.4 \\
CAJ & 25.5 & 17.8 & 11.5 \\
RAS & 26.7 & 16.4 & 6 \\
\hline
\end{tabular}




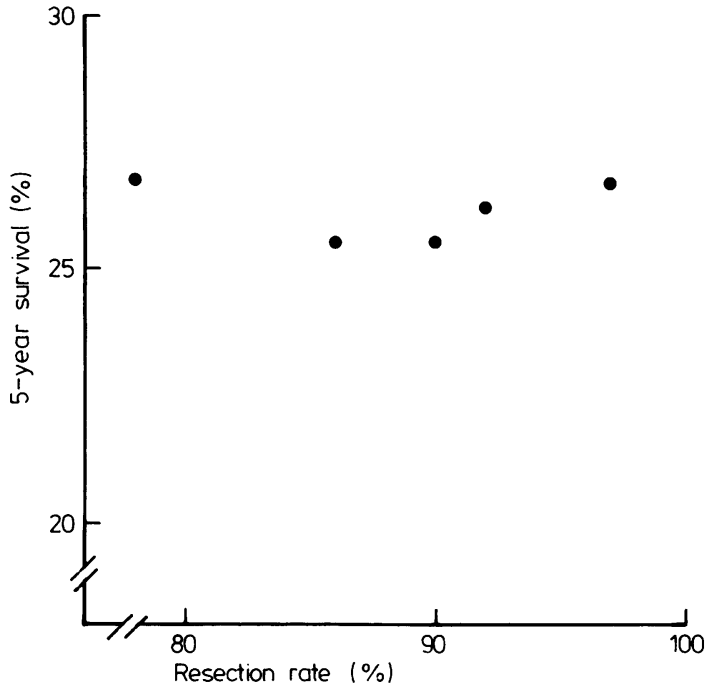

Fig 2 Relation of survival rate to resection rate among the surgeons contributing to this series.

\section{CAUSES OF LATE DEATH}

Data on the causes of late death, from RAS and JRB, are shown in table 4. In the first five years after operation a considerably higher proportion died of bronchial carcinoma in the series with the higher resection rate, as might have been expected; but after that the similarity between the two series is remarkable-particularly as two entirely different

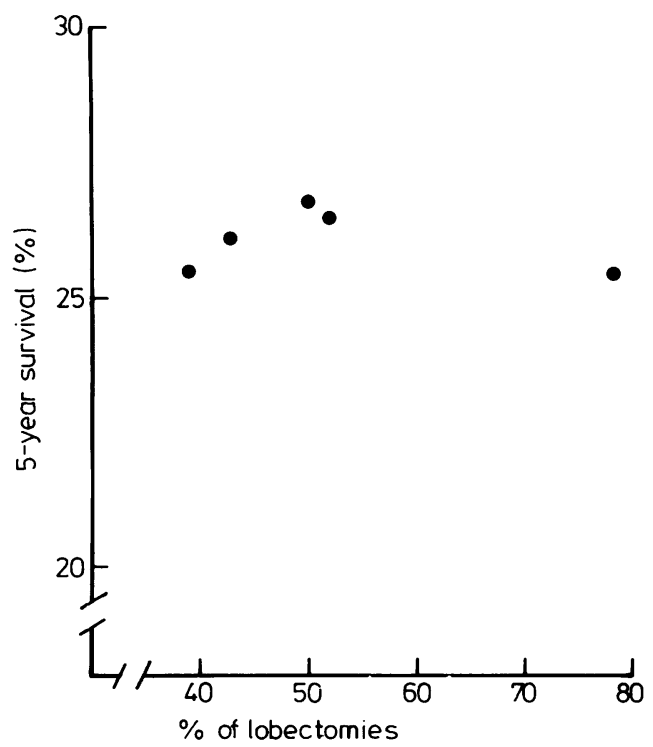

Fig 3 Relation of survival rate to the proportion of lobectomies done by the surgeons contributing to this series.

Table 4 Proportion of late deaths due to bronchial carcinoma

\begin{tabular}{lll}
\hline $\begin{array}{l}\text { Years after } \\
\text { resection }\end{array}$ & \% of late deaths \\
\cline { 2 - 3 } & RAS & JRB \\
\hline$<5$ & $95 \cdot 5$ & 79 \\
$5-10$ & $56 \cdot 0$ & 56 \\
$10-20$ & $35 \cdot 3$ & 35 \\
\hline
\end{tabular}

methods of finding the cause of death were used. In JRB's series copies of death certificates were sent from the Registrar General's Office to the hospitals concerned, whereas RAS $^{9}$ had seen his patients every four months after operation and when he was uncertain of the cause of death had sent health visitors to make personal inquiries.

\section{Discussion}

As bronchial carcinoma is so common and surgery offers almost the only hope of prolonged survival, it is surprising that so few large series have been reported. The largest personal collection is that of c. Bates, ${ }^{7}$ consisting of 2430 operations, which are included in the figures presented here. Figures from published papers reporting on more than 1000 cases are given in table 5 with the results presented here.

The differences in operative mortality reported here have been shown to be small. They are very similar to those reported from the United States and from other centres in Britain, where the UK Register of Thoracic Surgery for 1980 recorded a figure of $\mathbf{9 . 2 \%}$ for pneumonectomy. The mortality has tended to be higher in those series with a higher proportion of pneumonectomies and those which started earlier. All showed a lower mortality for lobectomy and there has been an improvement in the last two decades that coincides with better postoperative care. This observation was also made by Bignall et $a l^{10}$ and Wilkins et al. ${ }^{11}$

Table 5 Survival rates in series of more than 1000 operations

\begin{tabular}{|c|c|c|c|}
\hline Author & Total & $\begin{array}{l}\text { Resection } \\
\text { rate (\%) }\end{array}$ & $\begin{array}{l}\text { 5-year } \\
\text { survival (\%) }\end{array}$ \\
\hline 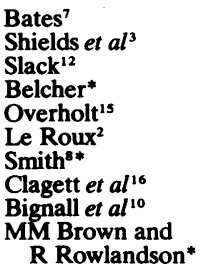 & $\begin{array}{l}2430 \\
2349 \\
2291 \\
2097 \\
1848 \\
1783 \\
1700 \\
1434 \\
1110 \\
1058\end{array}$ & $\begin{array}{l}91 \\
? ? \\
52 \\
79 \\
70 \\
82 \\
97 \cdot 5 \\
? ? \\
? ? \\
83\end{array}$ & $\begin{array}{l}26 \cdot 2 \\
27 \\
27 \\
26 \cdot 8 \\
25 \\
25 \cdot 6 \\
26 \cdot 7 \\
30 \cdot 3 \\
25 \cdot 5\end{array}$ \\
\hline
\end{tabular}


Resection rates varied more widely, ranging in this series from $78 \%$ to $97.5 \%$. The variation in previously published reports is greater, with one rate as low as $52 \% ; ;^{12}$ but this has no influence on the survival rate, as shown in this and other publications (table 5). This in turn confirms the importance of the policy first recommended by Abbey Smith of "resection at all costs." 48

This report also shows that the proportion of lobectomies had no influence on the survival rate. This too is confirmed in previous reports, the rate varying from $28 \%^{13}$ to $78 \%$ (MMB and RR) (fig 4). Thus the policy of "lobectomy where possible" has also been proved to be right.

The great similarity between survival rates at five years was first commented on in $1965^{14}$ and is amply confirmed in the series reported here, where the maximum difference in five large series was only $1.3 \%$. This similarity is mirrored in reports published worldwide: among reported series of more than 1000 operations the variation is only $5.3 \%$ and if the Mayo Clinic series ${ }^{16}$ is excluded it is only $2 \%$ (table 5).

As there are well-known variables, such as tumour size and the extent of glandular disease, which influence survival rates, the remarkable similarity of reported results implies that the proportion of patients with the different variants in any given series is likely also to have been similar. The staging

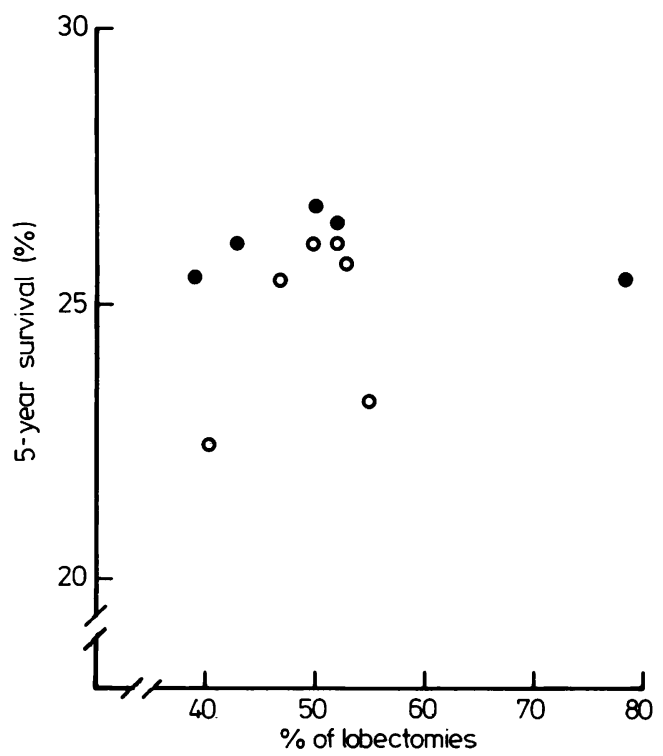

Fig 4. Relation of survival rate to the proportion of lobectomies in this series (closed circles) and six other published series (open circles).
Table 6 Survival rates at 10 years

\begin{tabular}{|c|c|c|}
\hline Author & Year & $\%$ \\
\hline $\begin{array}{l}\text { Ashor et al }{ }^{19} \\
\text { Shields and Robinette } \\
\text { Thompson } \\
\text { Vincent } \text { et }^{13} l^{1} \\
\text { Wilkins et } a l^{11}\end{array}$ & $\begin{array}{l}1975 \\
1972 \\
1960 \\
1976 \\
1978\end{array}$ & $\begin{array}{l}18 \\
14 \cdot 9 \\
16 \cdot 6 \\
14 \cdot 1 \\
19\end{array}$ \\
\hline
\end{tabular}

method advocated by Mountain ${ }^{17}$ was not used in this study and indeed can be used only for making comparisons between series and not for making clinical decisions, as it can be done only after thoracotomy. Nevertheless, a comparison of patients on this basis might confirm this observation.

It is depressing to see that there has been no improvement in the late results of surgery during the last 30 years. This has also been observed by Bignall $e t a l^{10}$ and Wilkins $e t a l ; ;^{11}$ indeed, only Paulson and Urschel ${ }^{18}$ have reported improved results. Mountain ${ }^{17}$ has said that a $55 \%$ chance of survival at five years can be held out to patients with small squamous-cell tumours; but this cannot be a basis for selection of patients for surgery, and despite great efforts in many centres with preoperative investigation and adjuvant treatment ${ }^{22}$ the position seems to be much the same as it was in 1950 .

For 10-year survival the difference between the highest and the lowest rates reported here was $4.2 \%$; the rates reported by other authors are largely within the same range (table 6). Many of these series were small, but again it is surprising how alike they are.

Lastly, the close similarity in the proportion of patients who died late after resection from bronchial carcinoma reported by the two surgeons who had this information ${ }^{80}$ is remarkable, being almost identical after five and 10 years. Perhaps even more surprisingly, Watson ${ }^{23}$ reported a difference of only $4 \%$ between five and 10 years and exactly the same after 10 years, although the numbers were small. Ashor $e t$ $a l^{19}$ also refers to the high risk of late death from bronchial carcinoma after resection; on the other hand, Shields and Robinette ${ }^{22}$ report a very different experience, with only $13 \%$ of their deaths after five years due to bronchial carcinoma. All have emphasised the importance of long-term follow-up in the light of these findings.

Thus not only the figures quoted here but also those published elsewhere show great similarity despite variations of geography, social customs, the age of the patients, the indications for operation, the resection rate, and the lobectomy rate. Nor have they changed significantly during the period under review, and the disease process itself must be the dominant factor influencing the results. 
My thanks are due to my friends and colleagues $M$ Bates, LL Bromley, M Meredith Brown, CA Jackson, R Rowlandson, and R Abbey Smith for their co-operation and hard work in providing most of the material for this study.

\section{References}

${ }^{1}$ Vincent RG, Takita H, Lane WW, Cutierrez AC, Pickren JW. Surgical therapy for lung cancer. $J$ Thorac Cardiovasc Surg 1976;71:581-91.

${ }^{2}$ Le Roux BT. Bronchial carcinoma. Edinburgh: Churchill Livingstone, 1968.

${ }^{3}$ Shields TW, Yee J, Conn JW, Robinette DC. Relationship of cell type and lymph node metastases to survival after resection for bronchial carcinoma. Ann Thorac Surg 1975;20:501-10.

${ }^{4}$ Smith RA. The results of raising the resectability rate in operations for lung cancer. Thorax 1957;12:79-86.

${ }^{5}$ Belcher JR. Lobectomy for bronchial carcinoma. Lancet 1956;i:349-53.

- Bates M. Segmental resection for bronchial carcinoma. Thorax 1975;30:235. (abstract).

${ }^{7}$ Bates M. Surgical treatment of bronchial carcinoma. Ann R Coll Surg Engl 1981;63:164-7.

${ }^{8}$ Smith RA. Evaluation of the long term results of surgery for bronchial carcinoma. J Thorac Cardiovasc Surg 1981;82:325-33.

${ }^{9}$ Smith RA. Development and treatment of lung cancer after successful lobectomy. Thorax 1966;21:1-20.

${ }^{10}$ Bignall JR, Martin M, Smithers DW. Survival in 6086 cases of bronchial carcinoma. Lancet 1967;i:1067-70.
"Wilkins EW, Scannell JG, Carver JG. Four decades of experience with resection for bronchogenic carcinoma at Massachusetts General Hospital. J Thorac Cardiovasc Surg 1978;76:365-8.

${ }^{12}$ Slack NH. Bronchogenic carcinoma: nitrogen mustard as a surgical adjuvant and factors influencing survival. Cancer 1970;25:987-1002.

${ }_{13}$ Thompson VC. Results of resection for bronchial carcinoma. Thorax 1960;15:5-6.

${ }^{14}$ Belcher JR, Anderson R. Surgical treatment of car- is cinoma of the bronchus. Br Med J 1965;i:948-54.

${ }^{15}$ Overholt RH, Heptune WB, Ashraf MM. Primary cancer of the lung: a 42 years' experience. Ann Thorac Surg 1975;20:511-9.

${ }^{16}$ Clagett OT, Allen TH, Spencer Payne W, Woolner LB. The surgical experience of pulmonary neoplasms - a ten year experience.J Thorac Surg 1964;48:391-400.

${ }^{17}$ Mountain CF. Assessment of the role of surgery for con- $\sigma$ trol of lung cancer. Ann Thorac Surg 1978;24:36573.

${ }^{18}$ Paulson DL, Urschel HC. Selectivity in the treatment of 0 bronchial carcinoma. J Thorac Cardiovasc Surg 1971;62:555-62.

${ }^{19}$ Ashor GL, Kern WH, Meyer BW, et al. Long term survival in bronchogenic carcinoma.J Thorac Cardiovasc Surg 1975;70:581-9.

${ }^{20}$ Belcher JR, Rehahn M. Late deaths after resection for $\varnothing$ bronchial carcinoma. Br J Dis Chest 1979;73:18-30.

${ }^{21}$ Smith RA. Long term clinical follow-up for surgery of bronchial carcinoma. Thorax 1970;25:62-76.

${ }^{22}$ Shields TW, Robinette CD. Long term survivors after resection for bronchial carcinoma. Surg Gynecol Obs tet 1973;136:759-62.

${ }^{23}$ Watson WL. Lung cancer. St Louis: CB Mosby, 1965. 